American Journal of Applied Sciences 5 (6): 750-754, 2008

ISSN 1546-9239

(C) 2007 Science Publications

\title{
Transition Metal Complexes of Derivatized Chiral Dihydro-1,2,4-triazin-6-ones. Template Synthesis of Nickel(II) Tetraaza-(4N-M) Complexes Incorporating the Triazinone Moiety
}

\author{
${ }^{1}$ Ahmad S. Abushamleh, ${ }^{1}$ Marwa M. Al-Aqarbeh, and ${ }^{2}$ Vector Day \\ ${ }^{1}$ Department of Chemistry, Hashemite University, P.O. Box 150459, Zarqa, Jordan \\ ${ }^{2} \mathrm{X}$-Ray Crystallography Laboratory, Department of Chemistry, University of Kansas \\ Lawrence, Kansas 66045-7582, USA
}

\begin{abstract}
Template reactions of (L)-3-acetyl-5-methyl-1-phenyl-4,5-dihydro-1,2,4-triazine-6- one (8a) or (L)-3-acetyl-5-benzyl-1-phenyl-4,5-dihydro-1,2,4-triazine-6-one (8b) with nickel(II) acetate in the presence of a suitable diamine such as: 1,3-diaminopropane, o-phenylenediamine, or ethylenediamine afforded square planar tetraaza nickel(II) complexes of the type 4N-M (Scheme 4). Single crystal Xray structural analysis of one of the complexes $(9 \mathrm{~b})$ revealed square planar geometry around the nickel ion and symmetrical coordination of the triazinone moieties. The complexes were characterized by elemental analyses, magnetic measurements, and electrical conductivities.
\end{abstract}

Key words: Triazinones, tetraaza complexes, template effect synthesis, nickel(II) complexes

\section{INTRODUCTION}

The chiral 4,5-dihydro-1,2,4-triazin-6-ones (e.g compound 1, Scheme 1) were prepared by reacting $\alpha$ amino esters with hydrazonoyl chlorides (precursors of nitrile imines, the reactive 1,3-dipolar species) in a onepot synthesis ${ }^{[1]}$. The respective 4,5-dihydrotriazinone oximes (e.g. compound 2, Scheme 1) were shown to be readily accessible via oximation of the $\mathrm{C} 3$-acetyl group using hydroxylamine. The oxime compounds(2) are capable of functioning as bidentate ligand systems, very much similar to 3,5-cyclohexadience-1,2-dione dioxime (3) or dimethylglyoxime (DMG) $)^{[2,3]}$

It has been found that the oxime (2) coordinates to metal ions such as $\mathrm{Ni}^{2+}$ in a bidentate fashion utilizing the amidrazone nitrogen $\mathrm{HN}(4)$ and the oxime nitrogen as the donor atoms. This occurred in concomitant with a carbon- carbon coupling between the benzylic carbon of one oxime ligand and the chiral carbon center of the

Scheme 1
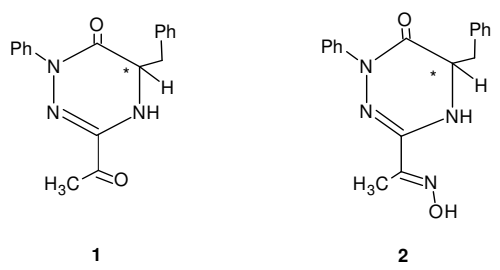

Scheme 2
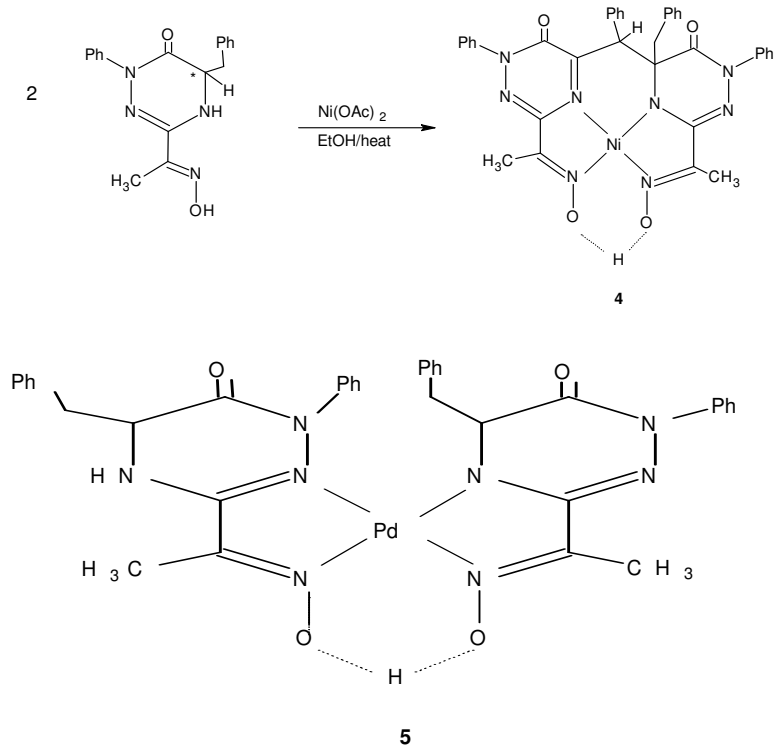

other oxime ligand (Scheme 2), the resulting structures (4) are square-planar dioxime complexes ${ }^{[4]}$.

Attempts to introduce $\mathrm{Pd}^{2+}$ ion instead of $\mathrm{Ni}^{2+}$ in (4) resulted in a square-planar palladium(II) complex where the two oxime ligands (2) are coordinated unsymmetrically and thus not allowing the expected carbon-carbon coupling to take place $(5)^{[5]}$.This has occurred probably due to the larger size of the $\mathrm{Pd}^{2+}$ ion

Corresponding Author: Ahmad S. Abushamleh, Hashemite University Department of Chemistry, P.O. Box 150459, Zarqa, Jordan 
Scheme 3

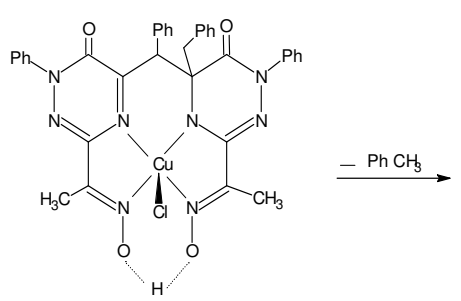

6

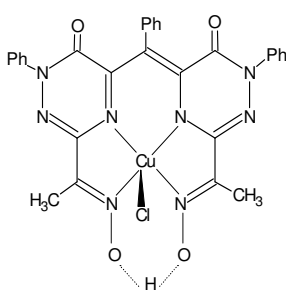

7 compared to $\mathrm{Ni}^{2+}$ and the pseudomacrocyclic cavity in (4) could not accommodate $\mathrm{Pd}^{2+}$.

In addition, the reaction of oxime (2) with copper(II) acetate gave complex (6) in minute quantities, apparently because toluene was eliminated from it giving rise to complex (7), (Scheme 3). The crystal structure of (7) was proved by X-ray crystallorgraphy and found to be slightly distorted square-pyramidal geometry ${ }^{[6]}$. This geometry was surprisingly supported by the presence of a chlorine atom bonded to the copper center. The source of this chlorine atom is not definitely known but it could be from the chlorinated solvent used in the preparation and crystallization processes ${ }^{[7]}$.

Since the overall aim of this work is to incorporate the triazinone moiety into a real macrocyclic ring system, we attempted a new synthetic route and that is the reaction of the triazinone compounds with suitable diamines in the presence of the transition metal cation, i.e.,template effect synthesis $^{[8]}$.

\section{RESULTS AND DISCUSSION}

It has been observed that in order for the carboncarbon coupling between the benzylic carbon of one triazinone ligand and the chiral carbon center of the other to take place, the two oxime ligands must coordinate in a symmetrical way (e.g. compound 4). This has initiated the idea of linking the two triazinone moieties from the bottom, using a suitable diamine, assuming that the carbon-carbon coupling will link them from the top. As such this should produce a macrocyclic ring system of a tetraaza-type (4N-M). Thus, two types of the 3-acetyl triazinones (compounds 8 ) and three types of diamines were used, these are: 1,3-diaminopropane, o-phenylenediamine, and ethylenediamine.<smiles>[R]C1NC(C(C)=O)=NN(c2ccccc2)C1=O</smiles>

\begin{tabular}{|c|c|c|}
\hline & $\mathrm{a}$ & $\mathrm{b}$ \\
\hline $\mathrm{R}$ & $\mathrm{CH}_{3}$ & $\mathrm{CH}_{2} \mathrm{Ph}$ \\
\hline
\end{tabular}

The reaction of two moles of the triazinone (8a) with one mole of 1,3-diaminopropane in the presence of one mole of nickel(II) acetate is expected to produce compound $9 \mathrm{a}$ or $9 \mathrm{~b}$ (Scheme 4). The nature of the product depends on whether cyclization, via carboncarbon coupling, has taken place or not. The resulting complex, however, is diamagnetic indicating square planar geometry for $\mathrm{Ni}^{2+}$. It is also neutral in $10^{-3} \mathrm{M}$ DMF solution. The IR spectral data are not diagnostic for such compounds. The elemental analyses indicate, most likely, an open-chain structure (9a). Similarly, two moles of the triazinone( $8 b)$ were reacted with one mole of 1,3-diaminopropane in the presence of one mole nickel(II) acetate. The produced oily/gummy product was purified until it was solid. The solid was recrystallized from hot aqueous methanol and the results of elemental analyses were consistent with structure $9 \mathrm{~b}$ which is neutral in $10^{-3} \mathrm{M}$ DMF solution. Magnetic measurements showed that $9 \mathrm{~b}$ is diamagnetic. In an attempt to grow crystals of $9 \mathrm{~b}$, several organic solvents were tried. The crystals used in the X-ray crystallographic analysis for the determination of the structure depicted in Fig. 1 were grown from acetone. When a sample of $9 \mathrm{~b}$ was recrystallized from dichloromethane, a much deeper color crystals were obtained. These deep color crystals are most likely compound 12 (Scheme 5), results of elemental analyses are consistent with structure 12 (for $\mathrm{Ni}_{32} \mathrm{H}_{27} \mathrm{~N}_{8} \mathrm{O}_{2}$ Calcd: C 62.57, H 4.40, N 18.25\%; Found: C 62.26, H $4.56, \mathrm{~N} 18.05 \%)$. Compound 12 is also diamagnetic and neutral in DMF. Attempts to grow crystals of the compound are still going on to prove the structure further by X-ray work.

The same synthetic roots (with minor variations) were employed when o-phenylenediamine and ethylenediamine were used to prepare compounds 10a, $10 \mathrm{~b}$ and $11 \mathrm{a}, 11 \mathrm{~b}$, respectively (Scheme 4). Apparantly, macrocyclic closure was not observed in these 
Scheme 4

\begin{tabular}{|c|c|c||c|c|c|}
\hline & $\mathrm{a}$ & $\mathrm{b}$ & & $\mathrm{a}$ & $\mathrm{b}$ \\
\hline $\mathrm{R}$ & $\mathrm{CH}_{3}$ & $\mathrm{CH}_{2} \mathrm{Ph}$ & $\mathrm{R}$ & $\mathrm{H}$ & $\mathrm{Ph}$ \\
\hline
\end{tabular}

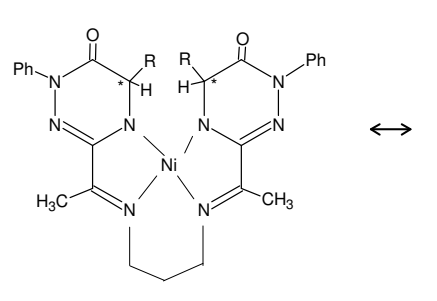

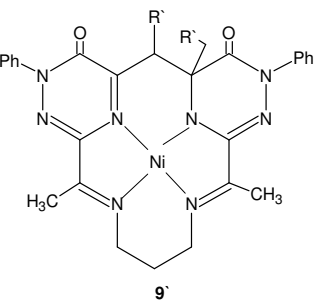

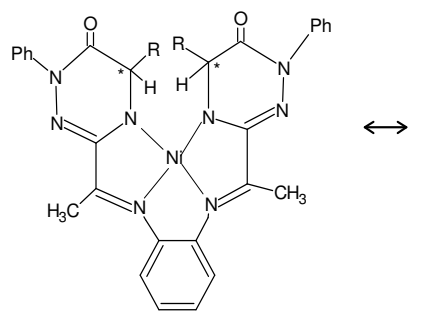

10

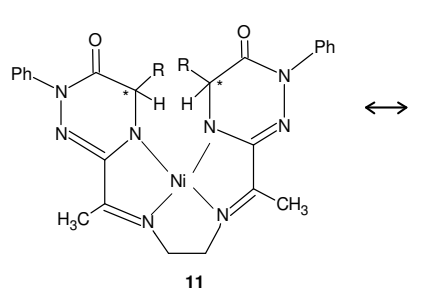

11

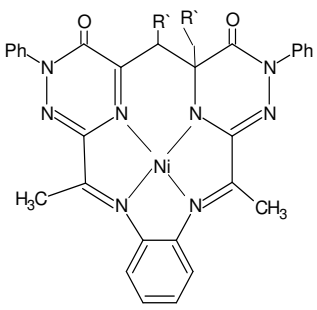

10

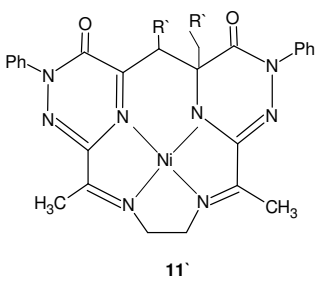

11
Scheme 5

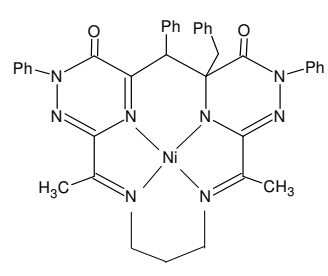

9'b

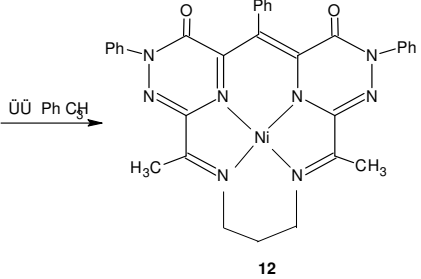

12 complexes, however, work is still going on to elucidate their structural features.

\section{CRYSTAL STRUCTURE DETERMINATION OF 9B}

Crystals suitable for X-ray crystallographic analysis were grown from acetone. The structure shown in Fig. 1 was determined at the $\mathrm{X}$-Ray Crystallography

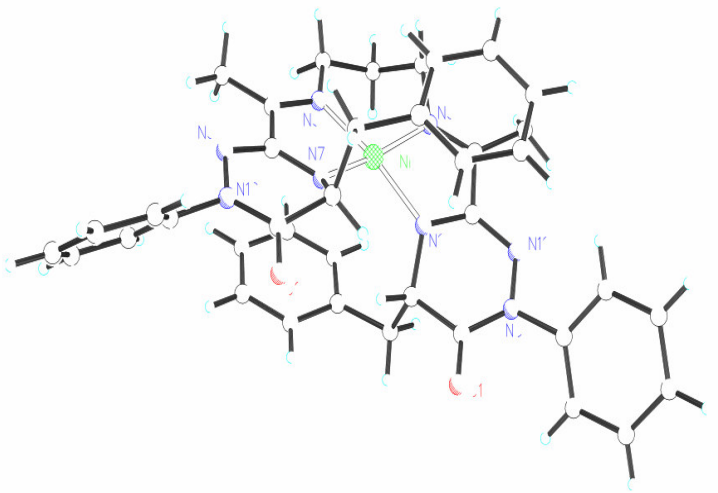

Fig. 1: Plot of the crystal structure of $9 \mathrm{~b}$

Laboratory, University of Kansas, USA. The absolute configuration that is shown was determined experimentally using anomalous dispersion of the $\mathrm{X}$ rays.

\section{EXPERIMENTAL}

Melting points (uncorrected) were determined using a Gallenkamp melting point apparatus in one-end glass capillaries. The magnetic moments were measured for finely ground solid samples at ambient temperature using a Johnson Matthey Magnetic Susceptibility Balance. Elemental analyses were performed on an Euro EA3000 Elemental Analyzer (Euro Vector), at the Department of Chemistry, Hashemite University, Jordan.

Synthesis of 1-phenylhyrazono-1- chloroacetone (Ph$\left.\mathrm{NH}-\mathrm{N}=\mathrm{C}(\mathrm{Cl})-\mathrm{C}(\mathrm{O})-\mathrm{CH}_{3}\right)(\mathrm{Hydrazonoyl}$ Chloride $)$ General procedure:

- Preparation of benzenediazonium chloride $\mathbf{P h N}_{2}{ }^{+} \mathbf{C l}^{-}$solution: Aniline $(0.1 \mathrm{~mol})$ in $80 \mathrm{ml}$ of 1:1 $\mathrm{H}_{2} \mathrm{O} /$ conc. $\mathrm{HCl}$ was cooled to about $0^{\circ} \mathrm{C}$ in an ice bath with stirring. Then a solution of sodium nitrite $\left(7.6 \mathrm{~g} / 25 \mathrm{~mL} \mathrm{H}_{2} \mathrm{O}\right)$ was added dropwise. Stirring was continued for $30 \mathrm{~min}$. This preparation was done according to reference 8 and the solution was used as it is in the next step.

- Reaction of benezenediazonium chloride with 3chloro-2,4-pentanedione: To a cold stirred solution $\left(-10^{\circ} \mathrm{C}\right)$ of 3-chloro-2,4- pentanedione (13.5g, $\left.0.1 \mathrm{~mol} / 80 \mathrm{~mL} \mathrm{H}_{2} \mathrm{O}\right)$, a cold solution $\left(-5^{\circ} \mathrm{C}\right)$ of benzenediazonium chloride was added gradually. Stirring of the resulting mixture was 
continued for 15 minutes. The crude solid product was collected by suction filtration and washed several times with cold water and then with little petroleum ether, dried and recrystallized from chloroform / petroleum ether. Yield $=15.1 \mathrm{~g}(79 \%)$; $\mathrm{mp} 140-14^{\circ} \mathrm{C}$; literature mp. $141-142{ }^{\circ} \mathrm{C}{ }^{[9]}$.

Synthesis of: L-3-Acetyl-5-methyl-1-phenyl-4,5dihydro $^{-[1,2,4]-}$ triazin-6-one $(\mathbf{8 a})$ : This compound was prepared via direct interaction between 1-chloro-1phenylhydrazono-2-propanone (hydrazonoyl chloride) and L-alanine methyl ester hydrochloride in the presence of triethylamine, according to the following general procedure:

To a stirred solution of the hydrazonoyl chloride (20 $\mathrm{mmol}$ ) in $50 \mathrm{~mL}$ of $\mathrm{CHCl}_{3}$, a solution of the appropriate amino acid ester hydrochloride $(20 \mathrm{mmol})$ in $50 \mathrm{~mL}$ of methanol was added. The mixture was cooled to about $0^{\circ} \mathrm{C}$ and triethylamine $(18 \mathrm{~mL}, 0.17 \mathrm{~mol})$ in $10 \mathrm{~mL}$ of methanol was added dropwise keeping the temperature not higher than $5^{\circ} \mathrm{C}$. The reaction mixture was kept under continuous stirring at $0^{\circ} \mathrm{C}$ for $2-3 \mathrm{~h}$. and then at ambient temperature for 24 hours. The solvent was then removed in vacuo, and the residue was washed with water. The resulting crude solid product was then collected and recrystallized from aqueous ethanol. The product was obtained in the form of prismatic crystals, $78 \%$ yield, mp $114-115^{\circ} \mathrm{C}$.

Synthesis of: L-3 Acetyl-5-benzyl-1-phenyl-4,5dihydro $^{-[1,2,4]-}$ triazin-6-one $(\mathbf{8 b})$ : The same procedure for compound (8a) above except that L-phenylalanine methyl ester hydrochloride was used. Yield (83\%), mp. 64- $66^{\circ} \mathrm{C}$.

N,N'-Bis [(1-phenyl-5-methyl-4,5-dihydro-6-oxo1,2,4-triazin-3-yl)-ethylidene] propane-1,3-diamine nickel (II) , (9a): The acetyl compound (8a) (1.39g, 6 $\mathrm{mmol})$ and nickel acetate tetrahydrate $(0.75 \mathrm{~g}, 3 \mathrm{mmol})$ in $80 \mathrm{~mL}$ of absolute ethanol were stirred at room temperature for few minutes. 1,3-diaminopropane $(0.24$ $\mathrm{g}, 3.25 \mathrm{mmol})$ in absolute ethanol $(20 \mathrm{~mL})$ was added dropwise over a period of $10 \mathrm{~min}$. The reaction mixture was brought to reflux under constant stirring for about 70 hours. During the first few hours the reaction mixture assumed dark green color which changed to red then to brown color. This color persisted until the end of the reflux time. The solvent was removed in vacuo, and a gummy residue was obtained. This was treated with hot aqueous ethanol and left aside to solidify. The crude solid was recrystallized from hot aqueous methanol. Yield $=1.15 \mathrm{~g}(70 \%), \mathrm{mp}>330^{\circ} \mathrm{C}$.

Anal: Calcd for $\mathrm{Ni} \mathrm{C}_{27} \mathrm{H}_{30} \mathrm{~N}_{8} \mathrm{O}_{2}$ (556.7), C 58.20, $\mathrm{H}$ 5.39, N 20.12\%

Found: C 57.07, H 5.99, N 20.07\%

N,N'-Bis [(1-phenyl-5-benzyl-4,5-dihydro-6-oxo1,2,4-triazin-3-yl)-ethylidene] propane-1,3-diamine nickel (II) , (9b): The acetyl compound (8b), (1.84g, 6 $\mathrm{mmol})$ and nickel acetate tetrahydrate $(0.75 \mathrm{~g}, 3 \mathrm{mmol})$ in $80 \mathrm{~mL}$ of absolute ethanol were stirred at room temperature for few minutes. 1,3-Diaminopropane $(0.24$ $\mathrm{g}, 3.25 \mathrm{mmol})$ in absolute ethanol $(20 \mathrm{~mL})$ was added dropwise over a period of $10 \mathrm{~min}$. The reaction mixture was brought to reflux under constant stirring for about $70 \mathrm{~h}$. During the first few hours the reaction mixture assumed dark green color which changed to red then to brown color. This color persisted until the end of the reflux time. The solvent was removed in vacuo, and a gummy residue was obtained. This was treated with hot aqueous ethanol and left aside to solidify. The solid was recystallized from hot aqueous methanol. Yield $=1.26 \mathrm{~g}$ $(60 \%), \mathrm{mp}>330^{\circ} \mathrm{C}$.

Anal: Calcd for $\mathrm{Ni} \mathrm{C}_{39} \mathrm{H}_{38} \mathrm{~N}_{8} \mathrm{O}_{2}$ (708.7), C 66.04, $\mathrm{H}$ 5.36, N $15.80 \%$

Found: C 67.07, H 5.56, N 15.64\%

N,N'-Bis [(1-phenyl-5-methyl-4,5-dihydro-6-oxo1,2,4-triazin-3-yl)-ethylidene] o-phenylenediamine nickel (II) , (10a): The acetyl compound (8a) $(1.39 \mathrm{~g}, 6 \mathrm{mmol})$ and nickel acetate tetrahydrate $(0.75 \mathrm{~g}, 3 \mathrm{mmol})$ in $60 \mathrm{~mL}$ of absolute ethanol were stirred at room temperature for few minutes. o-Phenylenediamine $(0.35 \mathrm{~g}, 3.25 \mathrm{mmol})$ in absolute ethanol $(20 \mathrm{~mL})$ was added dropwise over a period of $10 \mathrm{~min}$. The reaction mixture was brought to reflux under constant stirring for about 3 days. The reaction mixture assumed deep- red color which changed to brown then to black color. This color persisted until the end of the reflux time. The solvent was removed in vacuo, and the produced compound was recrystallised from dichloromethane. Fine powder was always obtained. Yield $=0.97 \mathrm{~g}(55 \%), \mathrm{mp}>$ $330^{\circ} \mathrm{C}$.

Anal: Calcd for $\mathrm{Ni} \mathrm{C}_{30} \mathrm{H}_{28} \mathrm{~N}_{8} \mathrm{O}_{2}$ (590.7), C 60.94, $\mathrm{H}$ 4.74, N $18.96 \%$

Found: C 60.07, H 4.56, N 18.64\%

N,N'-Bis [(1-phenyl-5-benzyl-4,5-dihydro-6-oxo1,2,4-triazin-3-yl)-ethylidene] o-phenylenediamine nickel (II) , (10b): The acetyl compound (8b), (1.84g, $6 \mathrm{mmol})$ and nickel acetate tetrahydrate $(0.75 \mathrm{~g}, 3$ 
$\mathrm{mmol}$ ) in $60 \mathrm{~mL}$ of absolute ethanol were stirred at room temperature for few minutes. o-Phenylenediamine $(0.35 \mathrm{~g}, 3.25 \mathrm{mmol})$ in absolute ethanol $(20 \mathrm{~mL})$ was added dropwise over a period of 10 minutes. The reaction mixture was brought to reflux under constant stirring for about 7 days. The reaction mixture assumed green color which changed to brown. This color persisted until the end of the reflux time. The solvent was removed in vacuo, and the product obtained was recrystallised from dichloromethane and deep brown powder was obtained. Yield $=1.14 \mathrm{~g}(50 \%), \mathrm{mp}>330^{\circ} \mathrm{C}$. Anal: Calcd for $\mathrm{Ni} \mathrm{C}_{42} \mathrm{H}_{36} \mathrm{~N}_{8} \mathrm{O}_{2}$ (742.7), C 67.86, $\mathrm{H}$ 4.85, N $15.08 \%$

Found: C 66.97, H 4.46, N 15.61\%

N,N'-Bis [(1-phenyl-5-methyl-4,5-dihydro-6-oxo1,2,4-triazin-3-yl)-ethylidene] ethane-1,2-diamine nickel (II) , (11a): The acetyl compound (8a) (1.39g, 6 mmol) and nickel acetate tetrahydrate $(0.75 \mathrm{~g}, 3 \mathrm{mmol})$ in $80 \mathrm{~mL}$ of absolute ethanol were stirred at room temperature for few minutes. Ethylenediamine $(0.20 \mathrm{~g}$, $3.33 \mathrm{mmol})$ in absolute ethanol $(20 \mathrm{~mL})$ was added dropwise over a period of 10 minutes. The reaction mixture was brought to reflux under constant stirring for about 3 days. During the first few hours the reaction mixture assumed red color and this color persisted until the end of the reflux time. The solvent was removed in vacuo, and an oily residue was obtained. This was treated with hot aqueous ethanol and left aside to solidify. The solid was recrystallized from acetone. Yield $=0.93 \mathrm{~g}(55 \%), \mathrm{mp}>330^{\circ} \mathrm{C}$

Anal: Calcd for $\mathrm{Ni} \mathrm{C}_{42} \mathrm{H}_{36} \mathrm{~N}_{8} \mathrm{O}_{2}$ (542.7), C 57.49, H 5.16, N 20.64\%

Found: C 57.97, H 5.46, N 20.11\%

N,N'-Bis [(1-phenyl-5-benzyl-4,5-dihydro-6-oxo1,2,4-triazin-3-yl)-ethylidene] ethane-1,2-diamine nickel (II) , (11b): The acetyl compound (8b), (1.84g, 6 $\mathrm{mmol})$ and nickel acetate tetrahydrate $(0.75 \mathrm{~g}, 3 \mathrm{mmol})$ in $80 \mathrm{~mL}$ of absolute ethanol were stirred at room temperature for few minutes. Ethylenediamine $(0.20 \mathrm{~g}$, $3.33 \mathrm{mmol})$ in absolute ethanol $(20 \mathrm{~mL})$ was added dropwise over a period of 10 minutes. The reaction mixture was brought to reflux under constant stirring for about 3 days. During the first few hours the reaction mixture assumed red color ans this color persisted until the end of the reflux time. The solvent was removed in vacuo, and an oily residue was obtained. This was treated with hot aqueous ethanol and left aside to solidify and the solid was recrystallized from acetone. Yield $=1.35 \mathrm{~g}(65 \%), \mathrm{mp}>330^{\circ} \mathrm{C}$
Anal: Calcd for $\mathrm{Ni} \mathrm{C}_{42} \mathrm{H}_{36} \mathrm{~N}_{8} \mathrm{O}_{2}$ (694.7), C 65.63, H 5.18, N $16.12 \%$

Found: C 64.97, H 5.66, N 15.67\%

\section{ACKNOWLEDGMENTS}

We wish to thank Mr Rami Shareah for drawing all chemical structures in this paper. One of us A.S.A. wishes to thank the Hashemite University, Jordan for financial support of the work.

\section{REFERENCES}

1. El-Abadelah, M.M., A.Q. Hussein and B.A. Thaher, 1991. Heterocycles From Nitrile Imines. Part IV. Chiral 4,5-Dihydro-1,2,4-Triazinones. Heterocycles, 32: 1879-1895.

2. Abushamleh ,A.S. and M.M. El-Abadelah, 2000. Synthesis and Characterization of the Nickel and Cobalt Complexes of New $\mathrm{BF}_{2}^{+}$Bridged 1,2-Benzoquinone Bis( $\alpha$-Dioxime) Macrocycles. J. Chem. Soc. Pak., 22: 293-298.

3. Lance, K.A., K.A. Goldsby and D.H. Busch, 1990. Effective New Cobalt(II) Dioxygen Carrieres Derived From Dimethylglyoxime by Replacement of the Linking Protons With $\mathrm{BF}_{2}$. Inorg. Chem., 29: 4537-4545.

4. Abushamleh, A.S., M.M. El-Abadelah and C.M.Mossmer, 2000. Transition Metal Complexes of Derivatized Chiral Dihydro-1,2,4-Triazinones. Part I. Nickel(II) Complex of (D)-3-Acetyl-5-phenyl-4,5dihydro-1,2,4-triazin-6-one. An Instant of A CarbonCarbon Coupling Reaction. Heterocycles,53: 1155-1165.

5. Abushamleh, A.S., M.M. El-Abadelah and C.M. Mossmer, 2000. Synthesis and Structural Characterization of Palladium (II) Complex with (L)-3Acetyl-5-benzyl-1-phenyl-4,5-dihydro-1,2,4-triazin-6one Oxime.Patrt(II). Heterocycles, 53: 1737-1744.

6. Abushamleh ,A. S., M.M. El-Abadelah, C.M. Mossmer and W. Voelter, 2002. Transition Metal Complexes of Derivatized Chiral Dihydro-1,2,4-Triazinones. Part II. Synthesis and Structural Charaterization of a Copper(II) Complex of (L)-3-Acetyl-5-benzyl-1-phenyl-4,5dihydro-1,2,4-triazin-6-one Oxime. Z. Naturforsch., 57b: 547-551.

7. Abussurah, A. S., M. Kilinga, T.Repo, M.Leskela, T. Debaerdemeker and B. Rieger , 2000. Inhibition of a Palladium(II) Catalyst Upon Formation of a di- $\mu$ chlorocomplex, Acta Crystallographica., C. 56: e44-e45.

8. Busch D.H., A.L. Vance and A.G. Kolchinski, 1996. Molecular Template Effect: Historical View, Principles and Perspectives. In Comprehensive Supramolecular Chemistry ( eds J. Sauvage and M. W. Hosseini ) Volume 9, pp.237-357. Pergamon, New york.

9. Yao ,H. C. and P. Resnick , 1962. Azo-hydrazone Conversion. I. The Japp-Klingemann Reaction. J. Am. Chem. Soc., 84: 3514-3522. 